\title{
Model for simulated training of laparoscopic gastroenterostomy ${ }^{1}$
}

Márcio Alencar Barreira', Delano Gurgel Siveira", Hermano Alexandre Lima Rocha'", Luiz Gonzaga de

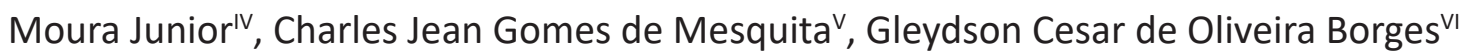

'MD, General Surgeon, Hospital Universitário Walter Cantídio, Fortaleza-CE, Brazil. Conception and design of the study; technical procedures; acquisition, interpretation and analysis of data; manuscript preparation and writing.

"MD, General Surgeon, Hospital Universitário Walter Cantídio, Fortaleza-CE, Brazil. Technical procedures, acquisition of data, critical revision.

I'IPhD, Assistant Professor, Professional Master's Degree Program in Minimally Invasive Technology and Simulation in Health, Centro Universitário Christus (UNICHRISTUS), Fortaleza-CE, Brazil. Conception and design of the study, statistical analysis, interpretation of data, critical revision.

IvPhD, Hospital Geral Dr. César Cals, Professional Master's Degree Program in Minimally Invasive Technology and Simulation in Health, UNICHRISTUS, Fortaleza-CE, Brazil. Conception and design of the study, critical revision.

${ }^{\vee}$ PhD, Professional Master's Degree Program in Minimally Invasive Technology and Simulation in Health, UNICHRISTUS, Fortaleza-CE, Brazil. Conception and design of the study, interpretation and analysis of data, critical revision, final approval.

VIMD, Holy House of Mercy of Fortaleza, Professional Master's Degree Program in Minimally Invasive Technology and Simulation in Health, UNICHRISTUS, Fortaleza-CE, Brazil. Conception and design of the study, interpretation and analysis of data, critical revision, final approval.

\section{Abstract}

Purpose: To develop a model of gastroenterostomy and to analyze the acquisition of skills after training by simulation.

Methods: Experimental longitudinal study and of a quantitative character. The sample consisted of twelve general surgery residents from four hospitals. The training consisted of making ten anastomoses divided equally into five sessions and it took place over a period of six weeks. The evaluation of the anastomoses considered the time and the analysis of the operative technique through the global evaluation scale Objective Structured Assessment of Technical Skills (OSATS). Results: Residents showed a reduction in operative time and evolution in the surgical technique statistically significant $(p<0.01)$. The correlation index of 0.545 and 0.497 showed a high linear correlation between time variables and OSATS.

Conclusion: The preparation of ten gastroenterostomies is an exercise capable of transferring basic and advanced skills in laparoscopy through a standardized training using synthetic organs and a simulator.

Key words: Models, Education. Anastomosis, Surgical. Gastroenterostomy. Laparoscopy. 


\section{Introduction}

The anastomosis among the stomach and the jejunum is an important procedure for the treatment or palliation of gastric cancer, and the laparoscopic approach is the preferred technique because it presents a lower morbidity and mortality than the open procedure $^{1}$. Anastomosis may be performed using staplers or manually, as no significant differences were observed in restoration of bowel function, length of hospital stay, and post-operative complications ${ }^{2}$.

Onewaytoreducesurgicalcomplications through simulation programs is to allow a safe and efficient environment to acquire desired surgical skills ${ }^{3}$ that are transferred to the operating room ${ }^{4}$. A recent systematic review of simulation in laparoscopic surgery covering 219 studies and 7.138 trainees concluded that simulated training in laparoscopy has great benefits when compared to no intervention ${ }^{5}$.

There is a general consensus among surgical educators that there is a need to standardize and improve the quality of teaching surgical skills for general surgery residents ${ }^{6}$, since most current residency programs do not guarantee that future surgeons will be able to complete complex laparoscopic procedures, such as a small intestinal anastomosis ${ }^{7}$.

In the last two decades, there has been a concern about the effectiveness of traditional medical education demonstrated through the search for the best performance of physicians so that the best results can be achieved in health care ${ }^{8}$. Recent reports from the World Health Organization on safety and quality of surgical performance emphasize the urgent need to improve training and certification to perform surgical procedures that are technology dependent, such as laparoscopic surgery ${ }^{9}$.

The introduction of a training model for residents interested in laparoscopy may be feasible for third world countries, giving hospitals with limited resources the opportunity to provide a means of surgical training that can positively influence the learning curve of general surgery residents ${ }^{10}$ and, thus reduce hospital costs ${ }^{11}$.

There is a tendency to seek additional training during and after General Surgery residency due to lack of confidence in the ability to treat surgical diseases by laparoscopy ${ }^{12}$. Therefore, the creation of an innovative model for the training of advanced laparoscopic surgery is justified. Thus, the objective of this research is to develop a model of gastroenterostomy in synthetic organs and to analyze the skills acquisition after a simulation training.

\section{- Methods}

This longitudinal experimental study was approved by the Research Ethics Committee of Centro Universitário Christus (number $1,317,965$ ) and Brazil platform system (Approval with CAAE number 49573215.7.0000.5049). This study respects the ethical precepts of human research and presents no possibility of damage to the physical, biological, psychic, moral, intellectual, social, cultural or spiritual dimension of the human being, at any stage of research or as a result of it.

The research was carried out in the Laboratory of Surgical Skills of Centro Universitário Christus, located in the city of Fortaleza, Ceará-Brazil. The simulations and data collection were carried out from January to March 2016 (Figure 1).

Seveteen residents of General Surgery at the end of the second year of training were recruited to participate in this study. The hospitals invited to participate in the study were: University Hospital Walter Cantídio (HUWC), General Hospital Dr. Cesar Cals (HGCC), General Hospital of Fortaleza (HGF) and Santa 
Casa de Misericórdia de Fortaleza (SCMF). Three residents had no interest in participating in the training and two residents were excluded because they did not complete the proposed training.

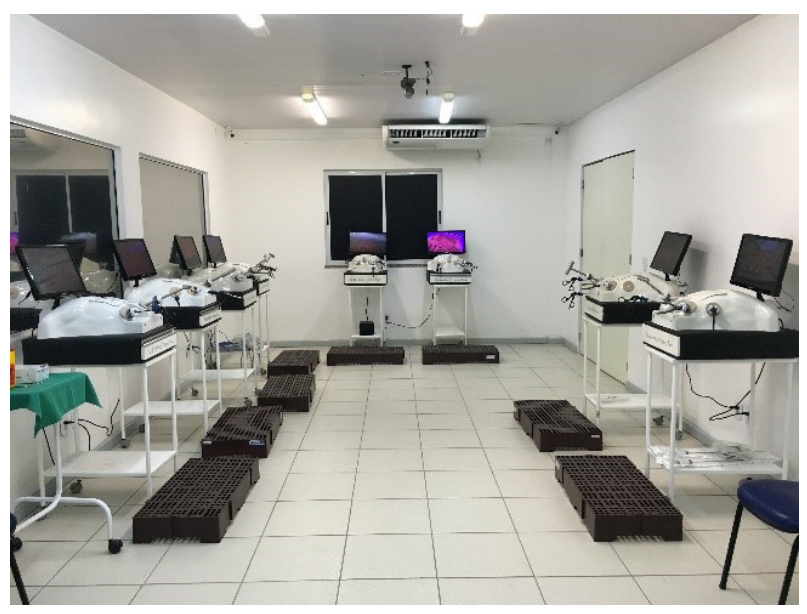

Figure 1 - Laboratory of surgical skills of Centro Universitário Christus.

\section{Surgical procedure}

After a first theoretical session consisting of a basic course of endosutures, videos and orientations, the residents began the training which aimed at the participation in the making of twenty anastomoses, being ten as main surgeon and ten as assistant surgeon. In order to reconcile the participants' schedules, the surgical team composed of two residents was chosen for convenience.

The positioning of the surgical team was defined so that everyone was using both hands and thus could interact throughout the procedure. The main surgeon positioned himself in front of the simulator and was entitled to use two portals which were located to the right and left of the optic portal. The assistant surgeon positioned himself on the right side of the simulator and was entitled of two portals, one between the portals of the main surgeon and at the midline level for the placement of the optic and the other on the left flank.

The organs used during training with the residents were a stomach and a segment of synthetic jejunum elaborated after several previous tests to the proposed training. The density has been improved so that the fabric composed of an elastomeric rubber achieves an adequate consistency and resistance for needle penetration. The conformation of the synthetic stomach was developing so that it had a cavity and a shape similar to the human organ. The small intestine had a diameter of 3 centimeters and 20 centimeters in length. The stomach was fixed to a plate on the left of the doctor in training and the small intestine segment loosened to the right.

The gastroenterostomy was carried out through a continuous suture in single plane with two Seda 3.0 wires. Each wire was 35 centimeters in length and had a gastrointestinal needle of 3 centimeters in diameter, and its choice was due to cost, availability and usability (Figure 2).

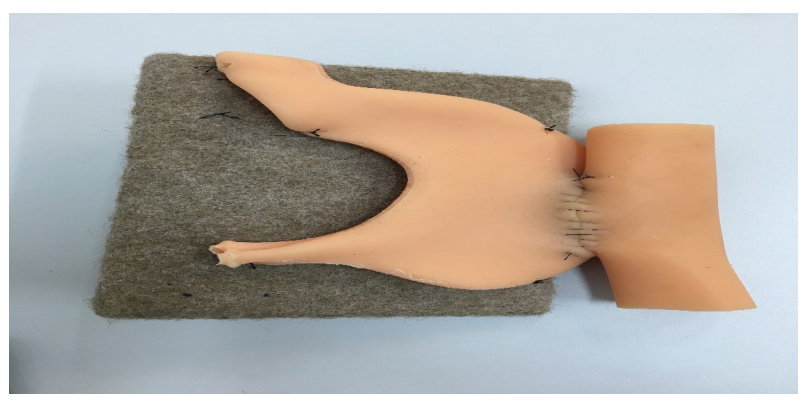

Figure 2 - Gastroenterostomy.

The training consisted of making ten anastomoses divided equally into five sessions and it took place over a period of six weeks. The simulation was performed in the EndosutureTrainning Box (ESTB) ${ }^{13}$.

There was the follow-up of an instructor who made positive feedback while stimulating and guiding the participants. The anastomoses that were recorded for further evaluation were 
the first and all the latest performed ones from the second training session. The recording began after the first tweezer was placed in the cavity and finished when the needle was withdrawn from the simulator after the anastomosis was made. Care was taken so that the videos had no audio and no part of the participants' body could be recognized. The videos were identified with a code consisting of the registration number and a letter that corresponded to the number of the anastomosis performed.

\section{Evaluation of anastomoses}

The judgment of the anastomoses made occurred in two stages. First the evaluator did a quantitative analysis using the time that the participant took to perform each anastomosis. In a second moment, a blind surgeon, through the analysis of the videos related to the exercises performed, evaluated the technical skill in making the anastomoses based on the global evaluation scale of the Objective Structured Assessment of Technical Skills (OSATS) evaluation ${ }^{14}$.

The global OSATS assessment scale is applied to any assessment of surgical skills and assesses knowledge, manipulation dexterity, and action record. It consists of seven items of assessment on a 5-point Likert scale ${ }^{15}$. The minimum score of each participant may be 7 points and the maximum of 35 points, having to reach 21 points or more to be considered competent in an individual task ${ }^{14}$.

\section{Pilot project}

Threesurgeons with experience in more than one hundred gastroenteroanastomoses in real patients were chosen who underwent a simulation in which they performed two anastomoses. The average of the best times of each surgeon was considered the optimal time to be reached at the end of the training.

\section{Statistical analysis}

The categorical quantitative results were presented as percentages and counts, and the numerical results were measured as central trend measures. Normality tests were performed for numerical variables. Depending on the normality of the variables, ANOVA or Mann-Whitney tests were performed, as appropriate. For categorical variables, the chi-square test was used. Simple linear regression and multiple analyzes were performed to verify the statistical significance of the correlations. Comparisons with $p$ value up to 0.05 were considered significant. The data were tabulated and analyzed by the SPSS software (Statistical Package for the Social Sciences), v23, SPSS, Inc. for the analysis and evaluation of the collected data.

\section{Results}

The majority of residents (74.9\%) were from Walter Cantídio University Hospital (41.6\%) and Fortaleza General Hospital (33.3\%). The Holy House (Santa Casa) of Fortaleza (16.6\%) and the General Hospital Dr. Cesar Calls (8.3\%) had a smaller participation. Participants were predominantly male $(83.4 \%)$ and had a mean age of 28 years (26-35 years).

In Figure 3, the average time of the first anastomosis of the residents (66 minutes) was well above the avegare time of the best anastomosis of the expert surgeons (26 $\mathrm{min}$ ). The value of $p<0.007$ shows that there is a statistically significant difference.

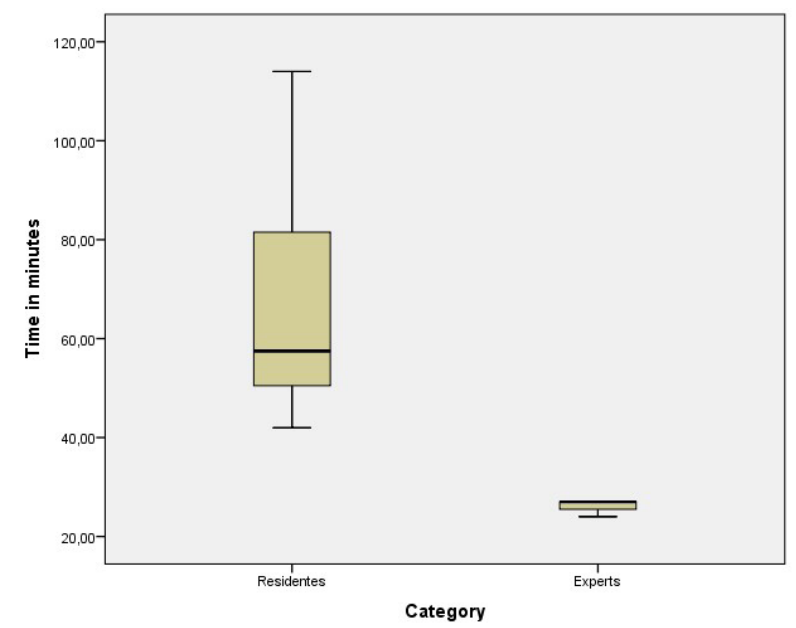

Figure 3 - Relationship between the mean time of the first anastomosis made by the residents and the best anastomosis of the experts.

Figure 4 shows that the mean time of the last anastomosis of the residents ( $27 \mathrm{~min}$ ) 
was very close to the average time of the best anastomosis of the expert surgeons (26 min). However, $p<0.687$ shows that there is no statistically significant difference.

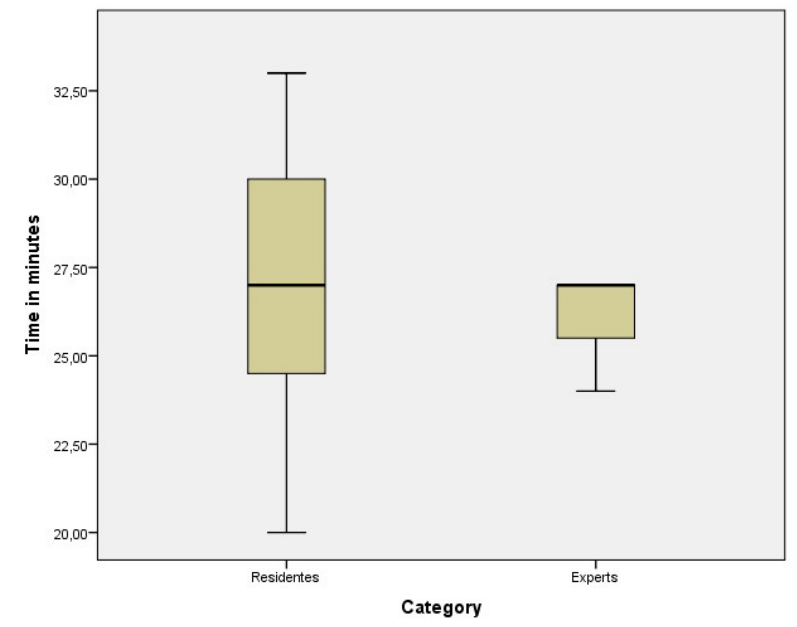

Figure 4 - Relationship between the average time to make an anastomosis between the last anastomosis performed by the residents and the best anastomosis performed by the experts.

The quality of the anastomosis improved during the training, as can be seen in Figure 5, which shows a statistically significant improvement $(p<0.01)$ in the OSATS scale score. The r of 0.497 represents a high linear correlation between the improvement in the OSATS scale score and the number of anastomoses made.

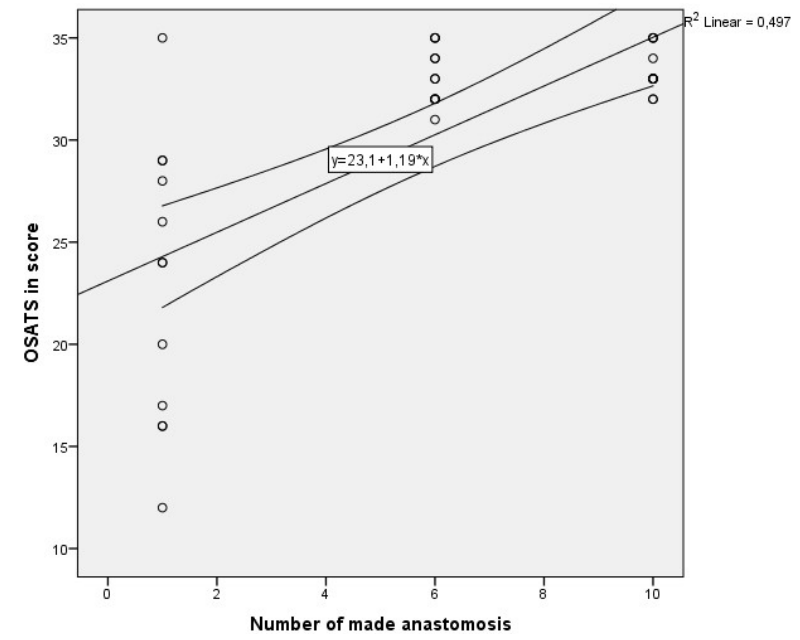

Figure 5 - Relationship between the number of anastomoses made and the score on the Osats scale.

\section{- Discussion}

The surgeon who intends to perform laparoscopic oncological procedures must have the ability to perform sutures and manual anastomoses, as adverse circumstances may occur during the operative event, and the absence of staplers is a common occurrence in Brazilian public hospitals.

The simulation should be inserted as early as possible into the curriculum of residents ${ }^{15}$ and the teaching of skills should be progressive, respecting the skill level of each individual ${ }^{16}$. The learning curve is different for each type of surgical procedure and it decreases for complex procedures when one has mastery over basic skills ${ }^{17}$. Therefore, endosuture compliance is fundamental for performing advanced surgical procedures, among which the gastrojejunal shunt is located $^{18}$.

A heterogeneity in the initial results is noted. During the preparation of the first anastomosis, it was observed that the residents presented a great variation in the time (42-114 $\mathrm{min}$ ) to perform an anastomosis by laparoscopy. However, at the end of the training the residents reduced this difference (20-33 min). It was observed that residents showed basic skills in laparoscopy, as the initial mean was 23 (7-35) points on the OSATS scale. The evolution of the surgical technique and the final quality of the anastomosis was important, resulting in the last operation an average score of 33.4 points on the OSATS scale.

The evaluation of the experts is important to serve as a parameter to be achieved $^{19}$, and the simulated training can lead the trainees to a similar level of the experienced specialists ${ }^{20}$. Residents presented a significant reduction in the operative time to make a gastroenterostomy, going from an initial average of 66,6 minutes to a final average of 27 minutes which was similar to the average time of the best anastomoses performed by the experts (26 minutes). 
Training improves the laparoscopic suturing skills of laparoscopy-exposed as well as laparoscopy-naïve surgeons and definitely helps in decreasing the learning curve. Prior experience in laparoscopic surgery does not seem to influence the acquisition of laparoscopic suturing skills, as laparoscopynaïve surgeons catch up with the skills of the laparoscopy-exposed surgeons ${ }^{21}$.

Three phases of learning of motor skills were described according to observations in practical sessions ${ }^{22}$. The first phase is related to a rapid acquisition of skills ${ }^{23}$. The second is the consolidation of learning ${ }^{24}$. Finally, in the last phase the skills gain is more gradual until it reaches a plateau that facilitates the retention of abilities ${ }^{22}$.

The first anastomosis was performed with an average of 66.6 minutes, while the fourth anastomosis took an average time of 38.8 minutes. Thus, in the first four anastomoses a rapid acquisition of abilities occurred. The eighth anastomosis was performed with an average of 27.6 minutes, while the tenth anastomosis took 27 minutes. Therefore, it can be considered that ten anastomoses is an approximate amount of the ideal to reach the plateau in the learning of a continuous anastomosis proposed for synthetic organs. The period that comprised between the fourth and eighth anastomosis was responsible for the consolidation of the necessary skills for the proposed anastomosis.

There are different levels of ability to acquire proficiency in a given procedure ${ }^{25}$. According to Grantcharov and Funch-Jensen ${ }^{26}$, there are four types of learning curves for the acquisition of technical skills: 1) individuals who demonstrate proficiency from the beginning of training; 2) people who achieve proficiency among two and nine repetitions; 3) a third group that can only gain proficiency after 10 repetitions and 4) a group that does not perform the skills from the beginning and shows no tendency of improvement.

In the data analysis, it was observed that a resident presented a time average in all the anastomoses (55 minutes) very different from the time average of all the anastomoses of the other residents (39 minutes), showing that this resident may require a longer training. An important fact is that all the residents managed to reduce the time considerably and that half of the residents were able to perform the anastomosis in a time that was less than the average of the experts.

According to Cristancho et al. ${ }^{27}$, the surgical simulation needs to identify a goal, systematize training taking into account available resources, use performance evaluation tools and perform evaluations with the purpose of validating the effectiveness of the proposed educational program.

Surgical training programs must be mandated by the government, facilitated by hospitals and developed and defined by medical societies. Thus, training in simulators needs to be part of the curriculum of residents who work in surgical specialties ${ }^{28}$.

This model is based in easily accessible materials. The material used was a rubber (elastomer) of low cost, and the price that the company charged us was $30 \$$ (each pack with stomach and intestine). The wire cost $\$ 0.5$ (Produced by a company located in Fortaleza). Training on a box trainer significantly decreased the learning curve necessary to learn laparoscopic suturing and is the more cost-effective option ${ }^{29}$.

We are still far from the American or European standard regarding the training of our residents in laparoscopic surgery. Considering the insufficient quantity and quality of courses and training centers in laparoscopic surgery, 
we are really faced with a real dilemma, a serious problem. The resolution is undoubtedly the greater integration of the teaching of laparoscopic surgery into residency programs. For this, we need the development of the preceptory and structure of services creation that work with education in surgery. It is now up to schools and services that offer medical residency to adapt to this need not only of doctors in medical training, but especially the population that wants to undergo less and less invasive surgical procedures ${ }^{30}$.

\section{- Conclusion}

The preparation of ten gastroenterostomies is an exercise capable of transferring basic and advanced skills in laparoscopy through a standardized training using synthetic organs and a simulator.

\section{References}

1. Zhang LP, Tabrizian P, Nguyen S, Telem D, Divino C. Laparoscopic Gastrojejunostomy for the treatment of gastric outlet obstruction. JSLS. 2011 Apr/Jun;15(2):16973. doi: $10.4293 / 108680811 X 13022985132$ 074.

2. Bangaru $H$, Veitla RMR, Pigilam $M$, Kunwargiri GK. Comparative study between staplers and conventional (hand-sewn) anastomosis in gastrointestinal surgery. Indian J Surg. 2012 Dec;74(6):462:7. doi: 10.1007/s12262-012-0450-7.

3. Aggarwal R, Darzi, A. Simulation to enhance patient safety: why aren't we there yet? Chest. 2011 Oct;140(4):854-8. doi: 10.1378/ chest.11-0728.

4. Vanderbilt AA, Grover AC, Pastis NJ, Feldman M, Granados DD, Murithi LK, Mainous AG. Randomized controlled trials: a systematic review of laparoscopic surgery and simulation-based training. Glob J Health Sci. 2015 Dec;7(2):310-27. doi: 10.5539/gjhs. v7n2p310.

5. Zendejas B, Brydges R, Hamstra SJ, Cook DA.
State of the evidence on simulation-based trainingforlaparoscopicsurgery: asystematic review. Ann Surg. 2013 Apr;257(4):586-93. doi: 10.1097/SLA.0b013e318288c40b.

6. Stain SC, Cogbill TH, Ellison EC, Britt LD, Ricotta JJ, Calhoun JH, Baumgartner WA. Surgical training models: a new vision. Curr Probl Surg. 2012 Oct;49(10):565-623. doi: 10.1067/j.cpsurg.2012.06.008.

7. Mattar SG, Alseidi AA, Jones DB, Jeyarajah DR, Swanstrom LL, Aye RW, Wexner SD, Martinez JM, Ross SB, Awad MM, Franklin ME, Arregui ME, Schirmer BD, Minter RM. General surgery residency inadequately prepares trainees for fellowship: results of a survey of fellowship program directors. Ann Surg. 2013 Sep;258(3):440-9. doi: 10.1097/ SLA.0b013e3182a191ca.

8. Nissen SE. Reforming the continuing medical education system. JAMA 2015 May;313(18):1813-4. doi: 10.1001/ jama.2015.4138.

9. Buzink S, Soltes M, Radonak J, Fingerhut A, Hanna G, Jakimowicz J. Laparoscopic surgical skills programmer: preliminary evaluation of Grade I Level 1 courses by trainees. Wideochir Inne Tech Malo Inwazyjne. 2012 Aug;7(3):188-92. doi: 10.5114/wiitm.2011.28895.

10. Long KL, Spears C, Kenady DE, Roth JS. Implementation of a low-cost laparoscopic skills curriculumina third world setting. J Surg Educ. 2014 Nov-Dec;71(6):860-4. doi: 10.1016/j.jsurg.2014.05.004.

11. Bashankaev B, Baido S, Wexner SD. Review of available methods of simulation training to facilitate surgical education. Surg Endosc. 2011 Jan;25(1):28-35. doi: 10.1007/s00464010-1123-x.

12. Coleman JJ1, Esposito TJ, Rozycki GS, Feliciano DV. Early subspecialization and perceived competence in surgical training: are residents ready? J Am Coll Surg. 2013 Apr;216(4):764-71. doi: 10.1016/j. jamcollsurg.2012.12.045.

13. Moura Junior LG. Modelo acadêmico de ensino teórico-prático em vídeo cirurgia, por meio de novo simulador real de cavidade abdominal (Tese). Programa de 
Pós-Graduação Stricto Sensu em Ciências Médico-Cirúrgicas, Faculdade de Medicina, Universidade Federal do Ceará; 2015.

14. Martin JA, Regehr G, Reznick R, MacRae $\mathrm{H}$, Murnaghan J, Hutchison C, Brown M. Objective structured assessment of technical skill (OSATS) for surgical Residents. Br J Surg. 1997 Feb;84(2):273-8. doi: 10.1046/j.13652168.1997.02502.x.

15. Chipman JG, Schmitz CC. Using objective structured assessment of technical skills to evaluate a basic skills simulation curriculum for first-year surgical residents. J Am Coll Surg. 2009 Sep;209(3):364-70. doi: 10.1016/j.jamcollsurg.2009.05.005.

16. Stefanidis D, Acker CE, Greene FL. Performance goals on simulators boost resident motivation and skills laboratory attendance. J Surg Educ. 2010 Mar-Abr;67(2):66-70. doi: 10.1016/j. jsurg.2010.02.002.

17. Stefanidis D1, Hope WW, Korndorffer JR Jr, Markley S, Scott DJ. Initial laparoscopic basic skills training shortens the learning curve of laparoscopic suturing and is cost-effective. J Am Coll Surg. 2010 Apr;210(4):436-40. doi: 10.1016/j.jamcollsurg.2009.12.015.

18. Aggarwal R, Hance J, Undre S, Ratnasothy J, Moorthy K, Chang A, Darzi A. Training junior operative residents in laparoscopic suturing skills is feasible and efficacious. Surgery. 2006 Jun;139(6):729-34. doi: http://dx.doi. org/10.1016/j.surg.2005.12.010.

19. Zevin B, Levy JS, Satava RM, Grantcharov TP. A Consensus-based framework for design, validation, and implementation of simulation-based training curricula in surgery. J Am Coll Surg. 2012 Oct;215(4):5806. doi: 10.1016/j.jamcollsurg.2012.05.035.

20. Varas J, Mejía R, Riquelme A, Maluenda F, Buckel E, Salinas J, Martínez J, Aggarwal R, Jarufe N, Boza C. Significant transfer of surgical skills obtained with an advanced laparoscopic training program to a laparoscopic jejunojejunostomy in a live porcine model: feasibility of learning advanced laparoscopy in a general surgery residency. Surg Endosc. 2012 Dec;26(12):3486-94. doi: 10.1007/s00464-
012-2391-4.

21. Bansal VK, Tamang T, Misra MC, Prakash P, Rajan K, Bhattacharjee HK, KumarS, Goswami A. Laparoscopic suturing skills acquisition: a comparison between laparoscopy-exposed and laparoscopy-naive surgeons. JSLS. 2012 Oct-Dec;16(4):623-31. doi: 10.4293/108680 812X13462882737375.

22. Korman M1, Raz N, Flash T, Karni A. Multiple shifts in the representation of a motor sequence during the acquisition of skilled performance. Proc Natl Acad Sci USA. 2003 Oct;100(21):12492-7. doi: 10.1073/ pnas.2035019100.

23. Karni A, Sagi, D. The time course of learning a visual skill. Nature. 1993 Sep;365(6443):2502. doi: 10.1038/365250a0.

24. Robertson EM. From creation to consolidation: a novel framework for memory processing. PloS Biol. 2009 Jan;7(1):e19. doi: 10.1371/journal. pbio.1000019.

25. Buckley CE, Kavanagh DO, Nugent E, Ryan D, Traynor OJ, Neary PC. The impact of aptitude on the learning curve for laparoscopic suturing. Am J Surg. 2014 Jan;207(2):26370. doi: 10.1016/j.amjsurg.2013.08.037.

26. Grantcharov TP, Funch-Jensen P. Can everyone achieve proficiency with the laparoscopic technique? Learning curve patterns in technical skills acquisition. Am J Surg. 2009 Apr;197(4):447-9. doi: 10.1016/j. amjsurg.2008.01.024.

27. Cristancho SM, Moussa F, Dubrowski A. A framework-based approach to designing simulation augmented surgical education and training programs. Am J Surg. 2011 Sep;202(3):344-51. doi: 10.1016/j. amjsurg.2011.02.011.

28. Schreuder HWR, Oei SG, Maas M, Borleffs JCC, Schijven MP. Implementation of simulation in surgical practice: minimally invasive surgery has taken the lead: the Dutch experience. Med Teach. 2011;33(2):105-15. doi: 10.3109/0142159X.2011.550967.

29. Orzech N, Palter VN, Reznick RK, Aggarwal $R$, Grantcharov TP. A comparison of 2 ex vivo training curricula for advanced laparoscopic 
skills: a randomized controlled trial. Ann Surg. 2012 May;255(5):833-9. doi: 10.1097/ SLA.0b013e31824aca09.

30. Nácul MP, Cavazzola LT, de Melo MC. Current status of residency training in laparoscopic surgery in Brazil: a critical review. Arq Bras Cir Dig. 2015 Jan-Mar;28(1):81-5. doi:

\subsection{0/S0102-67202015000100020.}

\section{Acknowledgements}

To the librarian Cynthia Rocha Brazil, and the engineer Regis Luiz Sabia de Moura.

\section{Correspondence:}

Márcio Alencar Barreira

Avenida Beira Mar, 2780/201

60165-121 Fortaleza-CE Brasil

Tel.: (55 85)99151-4975

drmarciobarreira@gmail.com

marciofmj@msn.com

Conflict of interest: none

Financial source: none
Received: Sep 19, 2016

Review: Nov 18, 2016

Accepted: Dez 20, 2016

${ }^{1}$ Research performed at Laboratory of Surgical Skills, Centro Universitário Christus University Center (UNICHRISTUS), Fortaleza-CE, Brazil. Part of Master degree thesis, Postgraduate Program in Minimally Invasive Technology and Health Simulation. Tutor: Gleydson Cesar de Oliveira Borges. 